\title{
EHMTI-0368. Treatment of migraine attacks as suggested by Dr. John R. Graham in 1955. A historical analysis with current implications
}

\author{
P Tfelt-Hansen ${ }^{1 *}$, E Loder ${ }^{2}$ \\ From 4th European Headache and Migraine Trust International Congress: EHMTIC 2014 \\ Copenhagen, Denmark. 18-21 September 2014
}

\section{Introduction}

In 1955 Dr. John R. Graham, an astute clinician, published 3 influential papers on migraine theories and mainly on treatment of migraine in the New England Journal of Medicine [1,2,3]. Many of Dr. Graham's clinical observations remain relevant to current methods of treating migraine attacks and some of his examples of suggestions are shown below.

Examples of suggestions on ergot therapy:

1 . The patient should be checked regarding to diagnosis of migraine and possible contraindications to ergot therapy.

2. The ergot dose should be carefully selected as the minimally effective dose.

3. The patient should be instructed to use ergot as early in the attack as he can make the diagnosis of "one of his migraine."

4. He should be urged to use the selected amount of ergot at the start rather than to distribute it over several hours.

5. Ergot derivatives should not be considered a failure until ergotamine tartrate has been given, early in an attack, by the parenteral route.

\section{Conclusion}

If the word "ergot" is replaced with" triptans" Dr. Graham thus seemingly anticipated in 1955 optimal modern acute treatment of migraine.

No conflict of interest.

${ }^{1}$ Neurology Danish Headache Center, Glostrup Hospital, Glostrup, Denmark Full list of author information is available at the end of the article

\author{
Authors' details \\ ${ }^{1}$ Neurology Danish Headache Center, Glostrup Hospital, Glostrup, Denmark. \\ ${ }^{2}$ J.R.Graham Headache Center, Harvard Medical School, Boston, USA. \\ Published: 18 September 2014
References
1. NEJM: $1955,253: 726-30$.
2. NEJM: $1955,253: 770-6$ \\ 3. NEJM: $1955,253: 814-21$. \\ doi:10.1186/1129-2377-15-S1-M11 \\ Cite this article as: Tfelt-Hansen and Loder: EHMTI-0368. Treatment of \\ migraine attacks as suggested by Dr. John R. Graham in 1955. A \\ historical analysis with current implications. The Journal of Headache and \\ Pain 2014 15(Suppl 1):M11.
}

Submit your manuscript to a SpringerOpen ${ }^{\mathcal{O}}$ journal and benefit from:

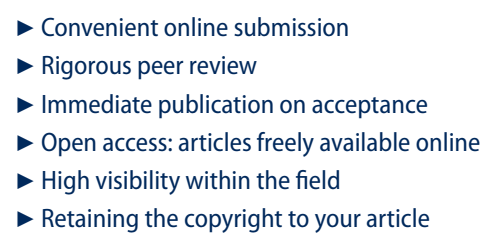

- Retaining the copyright to your article

Submit your next manuscript at $\boldsymbol{~ s p r i n g e r o p e n . c o m ~}$

\section{SpringerOpen ${ }^{\odot}$}

○ 2014 Tfelt-Hansen and Loder; licensee Springer. This is an Open Access article distributed under the terms of the Creative Commons Attribution License (http://creativecommons.org/licenses/by/2.0), which permits unrestricted use, distribution, and reproduction in any medium, provided the original work is properly cited. 